\title{
Multiprofissional electronic protocol in ophtalmology with enfasis in strabismus
}

\section{Protocolo eletrônico multiprofissional em oftalmologia com ênfase em estrabismo}

\author{
Christie Graf Ribeiro"; Ana Tereza Ramos Moreira ${ }^{1}$; José Simão de Paula Pinto²; Osvaldo Malafala, eCbC-PR³.
}

\begin{abstract}
A B S T R A C T
Objective: to create and validate an electronic database in ophthalmology focused on strabismus, to computerize this database in the form of a systematic data collection software named Electronic Protocol, and to incorporate this protocol into the Integrated System of Electronic Protocols (SINPE ${ }^{\odot}$. Methods: this is a descriptive study, with the methodology divided into three phases: (1) development of a theoretical ophthalmologic database with emphasis on strabismus; (2) computerization of this theoretical ophthalmologic database using SINPE $^{\oplus}$ and (3) interpretation of the information with demonstration of results to validate the protocol. We inputed data from the charts of fifty patients with known strabismus through the Electronic Protocol for testing and validation. Results: the new electronic protocol was able to store information regarding patient history, physical examination, laboratory exams, imaging results, diagnosis and treatment of patients with ophthalmologic diseases, with emphasis on strabismus. We included 2,141 items in this master protocol and created 20 new specific electronic protocols for strabismus, each with its own specifics. Validation was achieved through correlation and corroboration of the symptoms and confirmed diagnoses of the fifty included patients with the diagnostic criteria for the twenty new strabismus protocols. Conclusion: a new, validated electronic database focusing on ophthalmology, with emphasis on strabismus, was successfully created through the standardized collection of information, and computerization of the database using proprietary software. This protocol is ready for deployment to facilitate data collection, sorting and application for practitioners and researchers in numerous specialties.
\end{abstract}

Keywords: Protocols. Clinical Protocols. Data Collection. Ophthalmology. Strabismus.

\section{INTRODUCTION}

O ne of the biggest concerns and goals of medical educators for the next generation is to be able to demonstrate that knowing to better and faster perform the search for information is more important than trying to memorize and knowing the information itself. Discriminating what is good has become vital to finding the best routes and avoiding an "information shipwreck"1.

The practice of medicine is changing due to the more efficient use of biomedical literature in decision-making. Factors that may explain the growing interest in evidence-based medicine are the effectiveness and efficiency of new technologies in health associated with the ease of search in the scientific literature through computers².
The use of computer resources, especially with regard to the capture, storage and retrieval of clinical data, has been of great importance in the production of relevant and reliable clinical studies ${ }^{3}$. These databases enable structured collection of clinical information for later analysis and production of prospective studies of large series of patients.

The integration of technological advances in information and health sciences enabled the emergence of a new science, Bioinformatics, which has been instrumental in developing a specific literature ${ }^{4}$.

The Post-Graduate Program in Surgery of the Universidade Federal do Paraná (UFPR) articulates the practice, research and technology through a research line called "Computerized Protocols" and, since 1999, has improved the formatting and development of computerized protocols identified by the Acronym SINPE@ - Inte-

1 - Departamento de Oftalmologia da Universidade Federal do Paraná (UFPR), Curitiba/PR, Brasil; 2 - Departamento de Ciências e Informática da Universidade Federal do Paraná (UFPR), Curitiba/PR, Brasil; 3 - Departamento de Cirurgia da Universidade Federal do Paraná (UFPR), Curitiba/PR, Brasil. 


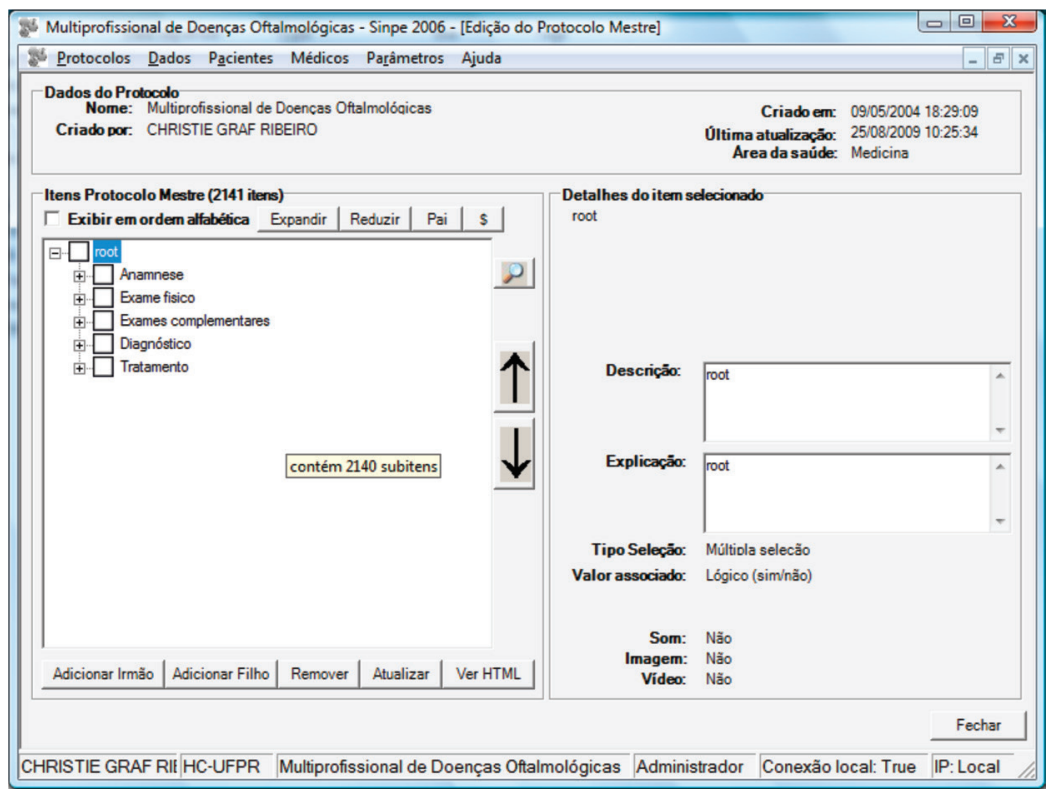

Figure 1. Master protocol screen.

grated Electronic Protocols, intellectual property of Professor Osvaldo Malafaia. The creation of a computerized clinical database, with the possibility of redemption and crossing of information, enables the production of scientific studies of high quality, credibility and less time spent on data research.

In the case of ophthalmology, the use of computers and, more particularly, the development of computer programs has been widely reported. However, few articles focus on electronic protocols. Ophthalmology needs constant research improvement. In this perspective, informatics is one of the ways that will enable new insights, questions and development in the knowledge of strabismus through research.

The objectives of this study are to create an electronic database in ophthalmology, with emphasis on strabismus, through standardized information gathering, and to computerize this basis in the form of software for the systematic collection of data called "Electronic Protocol" and incorporate this ophthalmology "Electronic Protocol" to the Integrated Electronic Protocols (SINPE@).

\section{METHODS}

The general aspects of the research were pre-established for strabismus diseases. We conducted the literature review in textbooks and by internet search in PubMed, Medline and LILACS. We opted for a direct and objective questionnaire, which was simple for the rapid and effective filling by the user.

There are 20 types of strabismus composing the database: alphabetical anisotropy, dissociated vertical deviation, accommodative esotropia, acquired comitant esotropia, congenital esotropia, restrictive strabismus, intermittent exotropia, constant exotropia, microtropia, other non-accommodative esotropias, other syndromes, other palsy type, paralysis of pair III paralysis of pair $\mathrm{IV}$, paralysis of pair $\mathrm{VI}$, supranuclear palsy, syndrome of the superior rectus muscle contracture, Brown syndrome, Duane syndrome and Mobius syndrome.

Figure 1 shows the main SINPE $@$ screen, which presents the menu bar, named as: Protocols, Data, Patients and Help. In the bottom of the screen there is the user name, the institution, the name of the protocol, user type and connection information. With the selection of the "Protocols" button, two items will appear as an option: master protocol and specific protocol. The master protocol is a set of hierarchically arranged items called "folders", to represent data that can be collected on a particular subject.

Specific protocols are also hierarchical clustering of items, but their goal is to contemplate the specific data of the researched subject. Thus, the specific protocol is a subset of a master protocol. The first item named root, which appears with the opening of the master protocol, is required so that the analyzer can read all the data to be analyzed. The five items of second order are the main folders: history, physical examination, laboratory tests, diagnosis and treatment. The ramifications were created from these folders.

The "add brother" button is used when one wants to include some data in the same order, and the button "add child" when one wants to add any item related to the selected data. The program works as a tree system and automatically adds the plus sign (+) next to 
the item that has sub-items (children). It cannot have items in the same order with the same name.

In the program, the one-choice items appear with a circle $(\mathrm{O})$ on the left, and the multiple choice ones are displayed in the same orientation with a square $(\square)$ for marking. The item "Teller Cards", for example, is multiple choice and therefore can be marked with "Cardiff Cards". The item 2021 , which is one-choice, may not be signaled to item 20/41.

Each item may contain text, sound, image and video. Files can be entered in the program via CD-ROM and DVD-R, and can be attached through connections, such as Internet, Bluetooth and infrared.

To create Congenital Esotropia

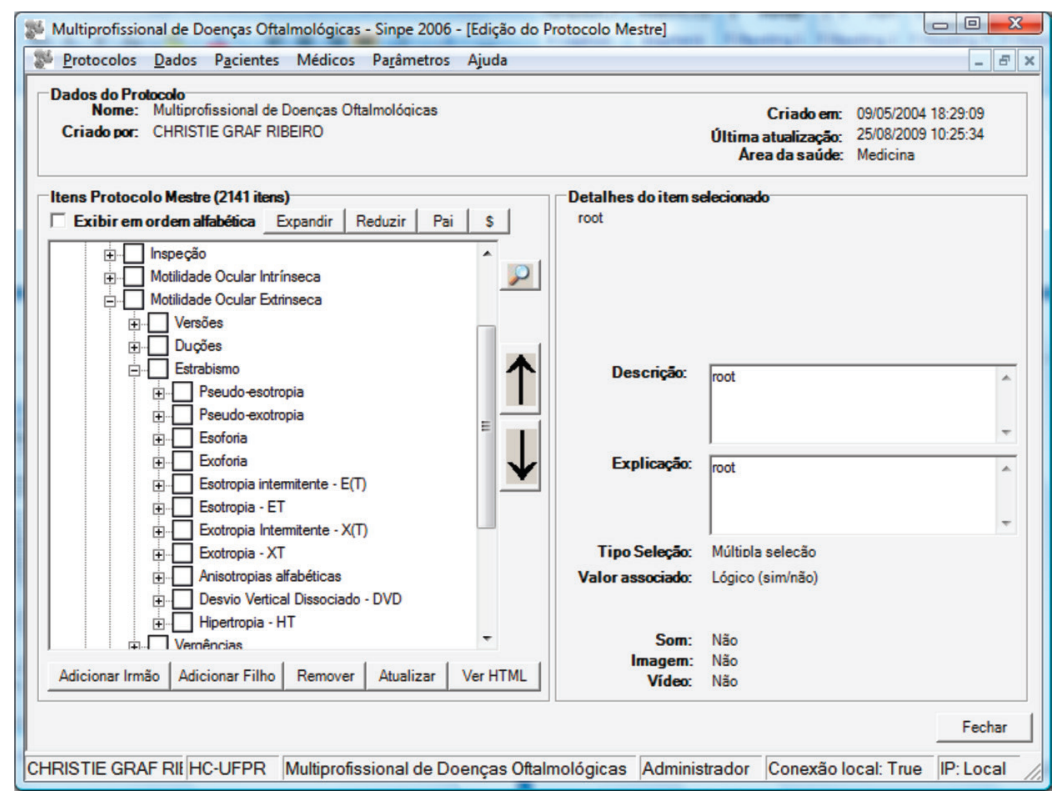

Figure 2. Strabismus item expanded.

Medical history was divided into: current protocol, for example, one must first select it. Then, it captures, via transmission arrows, the data of the master protocol relevant for this disease. Thus, all the disease characteristics will necessarily be included.

The system allows to collect, simulate and search data. The item "New Collection" offers the options of different specific protocols in addition to showing all registered patients in alphabetical order.

The summary sheet displays the name of the specific protocol, its master protocol, data analysis and name of the disk file for reference. To generate statistics and graphs, one clicks on "Incidence" and selects what branched item will be analyzed, being able to choose which type of chart to be generated (sectors, bars and / or line graph). It is therefore possible to select the form of graphic representation, as well as the collection of statistics for each item. The final step of the research provides the basis for description of the work "results".

\section{RESULTS}

In the master protocol, we placed all the 2141 relevant pieces of information pertaining to ophthalmology, with greater emphasis on strabismus. morbid history, clinical history, family morbid history, gestational history and perinatal history. Physical examination shows the complete eye examination: inspection, visual acuity, refraction, intrinsic ocular motility, extrinsic ocular motility, biomicroscopy, tonometry and ophthalmoscopy.

The inspection shows the signals that one must observe when examining the patient during an ophthalmologic consultation. In the folder "extrinsic ocular motility", the items describe the type of strabismus. Versions refer to binocular moves in the same direction and in the same sense. Ductions relate to the movements that one eye makes without taking into account what is happening with the other eye.

The "strabismus" item ranks strabismus in pseudoesotropia, pseudoexotropia, esophoria, exophoria, intermittent esotropia, esotropia, intermittent exotropia, exotropia, alphabetic anisotropy, dissociated vertical deviation, hipertropia (Figure 2).

The diagnosis includes medical, nursing and physiotherapy staff. Thus, since the same patient is assisted by several teams from different areas, we can have more comprehensive analysis of the patient's disease.

We also divided treatment in medical, nursing and physical therapy. Within medical, there is the "stra- 
bismus" folder, along with other ophthalmology folders. Within "strabismus" treatment is divided into: clinical, surgical, post-surgical evolution, surgical complications and referral to other specialists.

At the opening of the "surgical" item, right eye, for example, will show the extraocular, medial rectus, lateral rectus, superior rectus, inferior rectus, inferior oblique and superior oblique muscles. Within each muscle, all major types of techniques used to treat strabismus thereof.

After listing and inserting all the data that the program could possibly generate, we carried out a pilot data collection study related to the specific ophthalmology protocol with emphasis on strabismus for confirmation and interpretation of results. This comprised 50 samples taken in the sector of Ophthalmology of the Hospital Universitário da Universidade Federal do Paraná. We interpreted and presented the data through graphs by the SINPE@ Analyzer module. The program automatically analyzed the specific protocol selected, generating graphs, statistics and an analysis form.

Figure 3 shows an example of a collection of a patient who presented a visual acuity of 20/100 or 0.2 in the right eye measured with the uncorrected Snellen chart.

For a better explanation of the data generated by the SINPE@ analyzer module, the graphics have been

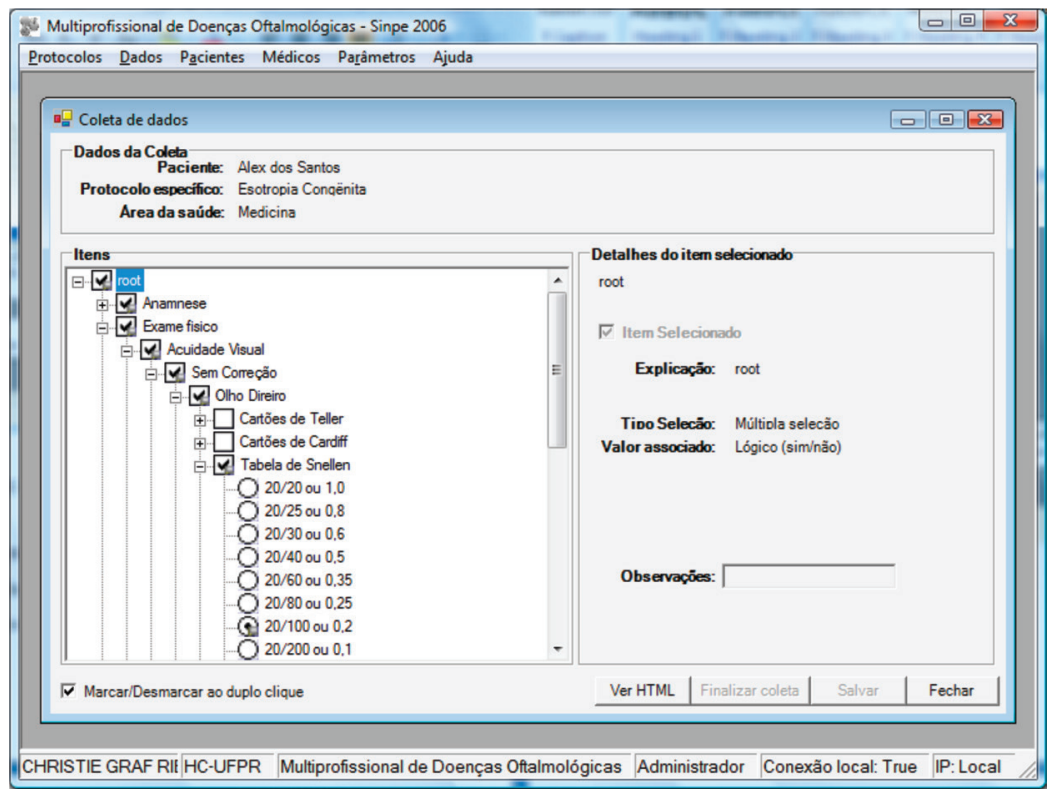

Figure 3. Sample Screen; item $20 / 100$ or 0.2 selected. adjusted, using the $X$ and $Y$ axes. Figure 4 shows the result of past morbid history automatically generated by the program.

\section{DISCUSSION}

We created an eye diseases multiprofessional protocol, in which we included strabismus. The selection of strabismus types used references considered as standard on the field study ${ }^{5,6}$. The use the data has obvious advantages in its compartmentalization between the general clinical practice and research. For example, examination of visual acuity has different goals in clinic and research. In the clinical setting, we want to get a good evaluation of how the patient is seeing and whether it is changing over time. The Snellen visual acuity chart is adequate for this task. But it does not provide data that are good for research. In research, the protocol requires the outcome of visual acuity obtained from the logarithm visual acuity card, usually after a refraction test. The data collected using the visual acuity from the EDTRS protocol (Early Treatment of Diabetics Retinopathy Study) is preferred in research ${ }^{7}$. In this study, beyond the Snellen chart and EDTRS, we included the Teller and Cardiff Cards for evaluation of visual acuity in the preverbal age.

The Ophthalmic Diseases Multidisciplinary Protocol with Emphasis on Strabismus followed the principles derived from the software created by Malafaia, following guidelines similar to the ones already developed $^{8}$. These principles relate to the application of electronic protocols, able to generate a quality database in a prospective and multicentric way, characterized by simplicity in form filling, as shown in this work, similar to that found by Sigwalt. According to Ribeiro ${ }^{9}$, the Integrated Electronic Protocols - SINPE@ - is an important technological tool, since it facilitates the ordering of data and provides multiprofessionality and specificity to research. This is what we seek with the current work. 


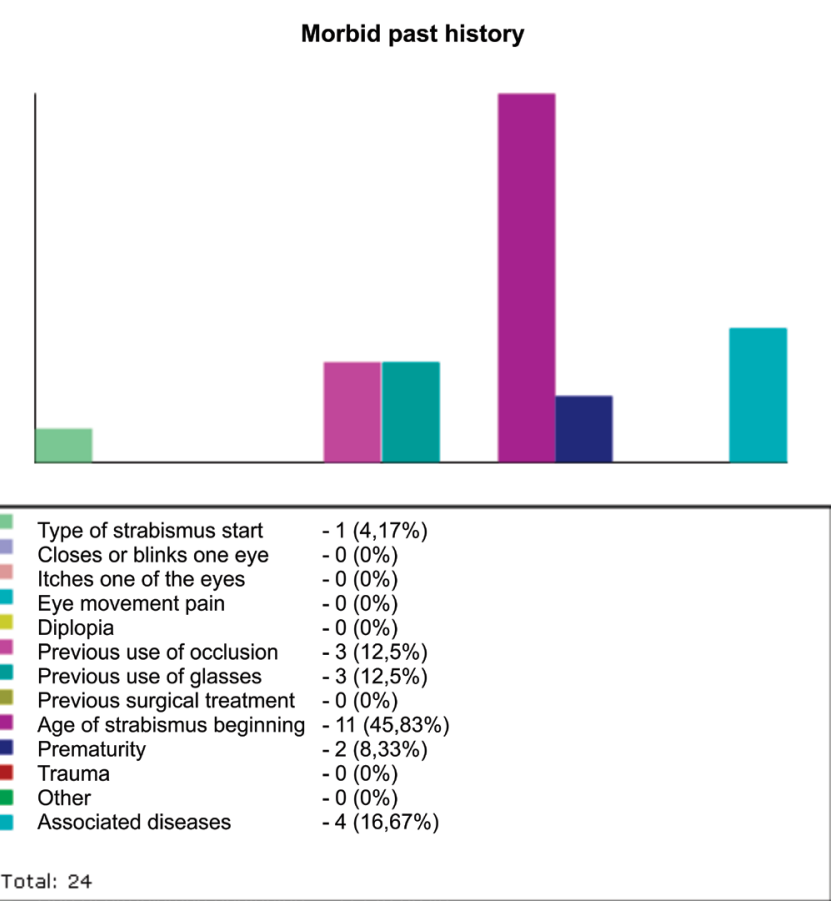

Figure 4. Morbid past history of patients with congenital esotropia.

The electronic protocol has numerous advantages over the conventional chart paper, among them is the ability to have full access to patient information at any time and anywhere, and save human and financial resources, as shown by Aylward and Parmar ${ }^{10}$.

The security of stored data is one of the crucial points of electronic records. Currently, there is already in Brazil a detailed regulation on the subject, to safeguard the confidentiality of the reported clinical data. According to Borsato, the multicenter use of SINPE( through the Internet must be safe ${ }^{11}$. SINPE( has a special concern to this matter, with several tools that enable confidentiality and protection of entered data.

In this work, the ease of use of protocols for data collectors is justified by the simplicity of the software, which presents with closed items. These days, most people have enough digital knowledge required for handling computers. Therefore, there are no barriers or the need for intensive specific training to the device use.

In Extrinsic Ocular Motility sector of the Department of Ophthalmology, Faculdade de Ciências Mé- dicas da Santa Casa de São Paulo, were registered 304 records of patients operated for esotropia. To register patients in the program, a questionnaire was elaborated with the relevant clinical variations in this type of deviation. In our study, we developed 20 specific strabismus protocols, with all possible clinical variations of deviations ${ }^{12}$.

This work enables the insertion of images, videos and sounds. This facilitates understanding by the examiner, which will analyze the various diagnostic positions of the extraocular muscles, in addition to the values of the deviations noted in the protocols. In addition, the study through images by more than one examiner lowers the chances of erroneous conclusions, as well as serves as a basis for comparison with the future state of this patient.

SINPE@ enables on-site and online collections, and searches can be determined to cover a specified subject, or one can specify certain characteristics to be observed. This gives great flexibility when it comes to clinical research, for it can be held in places of interest that have connections to internet data transmissions. Recently Internet II has been launched, linking Unifesp, Unicamp, USP, Incor, PUC and Papesp, enabling real time collaboration, with discussion of interactive tests. The same is seen in the work of Belfort Jr and Schor, where virtual doctors begin to be a reality and may carry out the activity anywhere, without leaving home ${ }^{1}$. The SINPE@ electronic protocol in cervical cancer was created in the Santa Casa de Misericórdia de Sao Paulo, with insertion of 2,687 items $^{13}$.

The experimental use of specific protocols reinforced the need for use of computerized systems for credible work, which is consistent with Grimson, who says the control and standardization of data on protocols allow prospective and longitudinal studies. These, with records accessible on the internet along with clinical protocols and guidelines, could be connected to direct individuals' health care ${ }^{14}$.

This database will critically 'provide relevant research in the field of ophthalmology, as the protocols presented are instruments that have quality, credibility and reliable information. 
We can conclude that, with the making of an ophthalmic diseases multidisciplinary electronic protocol with emphasis on strabismus, we created an electronic database in ophthalmology with emphasis on strabismus through standardized information gathe- ring. The computerization of this database was made in the form of software, so that future users will be able to use the ophthalmic diseases multidisciplinary electronic protocol with an emphasis on strabismus to collect data..

\title{
R E S U M O
}

\begin{abstract}
Objetivo: criar uma base eletrônica de dados em oftalmologia com ênfase em estrabismo através da coleta padronizada de informações. Informatizar esta base sob a forma de software para a coleta sistemática de dados chamado "Protocolo Eletrônico" e incorporar este "Protocolo Eletrônico" da Oftalmologia ao Sistema Integrado de Protocolos Eletrônicos (SINPE ${ }^{\odot}$ ). Métodos: este é um estudo descritivo e a metodologia aplicada em seu desenvolvimento está didaticamente dividida em três fases: 1) criação da base teórica de dados clínicos de oftalmologia com ênfase em estrabismo; 2) informatização da base teórica dos dados utilizando o SINPE ${ }^{\oplus}$; e 3) interpretação das informações com demonstração dos resultados. A informatização da base de dados foi realizada pela utilização da concessão de uso do SINPE ${ }^{\odot}$. Foram incluídos neste protocolo 50 pacientes com estrabismo para validação do protocolo. Resultados: o protocolo eletrônico desenvolvido permitiu armazenar informações relacionadas à anamnese, exame físico, exames complementares, diagnóstico e tratamento de pacientes com doenças oftalmológicas, com ênfase em estrabismo. Foram incluídos neste trabalho 2141 itens no protocolo mestre e foram criados 20 protocolos específicos de estrabismo, cada um com suas particularidades. Os 50 pacientes que foram incluídos nos protocolos específicos demonstraram a eficácia do método empregado. Conclusão: foi criada uma base eletrônica de dados em oftalmologia com ênfase em estrabismo através da coleta padronizada de informações. Esta base de dados foi informatizada sob a forma de software onde os futuros usuários poderão utilizar o protocolo eletrônico multiprofissional de doenças oftalmológicas com ênfase em estrabismo para a coleta de seus dados.
\end{abstract}

Descritores: Protocolos. Protocolos Clínicos. Coleta de Dados. Oftalmologia. Estrabismo.

\section{REFERENCES}

1. Belfort Jr R, Schor P. Programas inteligentes, inteligência artificial e oftalmologia. Arq Bras Oftalmol. 2000;63(4):253-4.

2. González De Dios J. From evidence-based medicine to medicine-based evidence. An Esp Pediatr. 2001;55(5):429-39.

3. Haux R, Ammenwerth E, Herzog W, Knaup P. Health care in the information society. A prognosis for the year 2013. Int J Med Inform. 2002;66(13):3-21.

4. Shortliffe EH, Blois MS. The computers meets medicine and biology: emergence of a discipline. In: Shortliffe EH, Cimino JJ, editors. Biomedical Informatics. New York: Springer Verlang Wesley; 2006.

5. Díaz JP, Souza-Dias C. Estrabismo. 4a ed. São Paulo: Santos; 2002.

6. Taylor D, Hoyt CS. Pediatric ophthalmology and strabismus. 3rded. London: Elsevier; 2005.

7. Murphy EC, Ferris LF III, O'Donnell WR. An eletronic medical records system for clinical research and EMR-EDC interface. Invest Ophthalmol Vis Sci. 2007;48(10):4383-9.

8. Malafaia O, Dietz UA, Ribas Filho JM, Czeczko NG, Borsato EP, Pinto JSP, et al. Elektronische datenerfassung im bereich der klinischen forschung, lehre und ärztlichen verwaltung in dem krankenhaus der zukunft. In: Thiede A, Gassel HJ, editors. Krankenhaus der zukunft. Heidelberg: Kaden Verlag; 2006. v.1. p.609-12.

9. Ribeiro ER. Protocolo eletrônico de coleta de dados para pesquisa em enfermagem médico-cirúrgica [dissertação]. Curitiba: Universidade Federal do Paraná, Programa de Pós-Graduação em Clínica Cirúrgica; 2004.

10. Aylward GW, Parmar DN. Information technology in ophthalmology--experience with an eletronic patient record. Br J Ophthalmol. 1999;83:1264-7.

11. Borsato EP. Modelo multicêntrico para elaboração, coleta e pesquisa de dados em protocolos eletrônicos [disserftação]. Curitiba: Universidade Federal de Paraná, Programa de Pós-Graduação em Clínica Cirúrgica; 2005. 
12. Garcia PN, Goldchmit M, Souza-Dias CR. Projeto piloto de informatização dos prontuários do setor de motilidade ocular extrínseca da Santa Casa de São Paulo. Arq Bras Oftalmol. 2008;71(4):504-8.

13. Fernandes GL, Santos RE, Malafaia O, Aoki T. Criação de protocolo eletrônico em câncer de colo de útero. Rev Col Bras Cir. 2012;39(1):28-32.

14. Grimson J. Delivering the eletronic healthcare record for the 21st century. Int J Med Inform. 2001;64(2-3):111-27.
Recebido em: 08/02/2016

Aceito para publicação em: 28/04/2016 Conflito de interesse: nenhum.

Fonte de financiamento: nenhuma.

\section{Endereço para correspondência:}

Christie Graf Ribeiro

E-mail: christie.graf@terra.com.br 